\title{
The impact of gunshots on place-level business activity
}

\author{
Christina Stacy ${ }^{1}$, Yasemin Irvin-Erickson ${ }^{2^{*}}$ and Emily Tiry ${ }^{3}$
}

\begin{abstract}
Objectives: Gun violence can negatively affect business activity at the place-level through a variety of mechanisms. However, estimating this effect is difficult since reported crime data are biased by factors that are also associated with business health. Despite some of its limitations, data from gunshot detection technology has been shown as a new valuable source of data on gun violence (Irvin-Erickson et al. in Appl Geogr 86: 262-273, 2017a). In this study, we use gunshot detection data to explore the spatial relationship between gunshots and business activity at the neighborhood level in Washington, DC between 2010 and 2012.

Methods: In this exploratory study, we create spatial buffers of 500 and 1000 feet around each block and sum up the total number of gunshots and business births, deaths, sales, and number of employees within these buffers each year and estimate a spatial fixed effects panel model.

Results: Gunshots within 1000 feet of a block increase the number of business deaths by $4.3 \%$ within that buffer on average, and gunshots within 500 feet of a block decrease the total number of service and retail businesses, the number of employees employed by businesses within that buffer, and total sales for those businesses (although not at a statistically significant rate). Gunshots on blocks with the lowest initial levels of gunshots increase business turnover and reduce the total number of businesses present by $0.5 \%$, and gunshots on blocks with the highest initial levels of gunshots cause an increase in the number of business deaths by $7.5 \%$.
\end{abstract}

Conclusion: Results suggest that efforts to improve distressed neighborhoods should target both areas with lower and higher pre-existing levels of gunshots.

Keywords: Gunshots, Business, ShotSpotter, Spatial econometrics

\section{Introduction}

Crime, particularly violent crime, has been shown to impose a variety of economic costs on individuals, communities, and society as a whole. These costs include increased health care costs (Howell et al., 2014; Miller et al., 1993), costs associated with lost productivity (Cook et al., 1999), costs associated with police, courts, and correctional institutions (Cook \& Ludwig, 2000; Shapiro \& Hassett, 2012), reduced property values (Hipp et al.,

*Correspondence: yirviner@gmu.edu

2 Department of Criminology, Law and Society, George Mason University, 4400 University Dr, Fairfax, VA 22030, USA

Full list of author information is available at the end of the article
2009; Irvin-Erickson, Lynch, et al., 2017; Kirk \& Laub, 2010; Lynch \& Rasmussen, 2001; Shapiro \& Hassett, 2012; Tita et al., 2006), lost time from work (Cook \& Ludwig, 2000; Perkins et al., 1996), and costs associated with victims' efforts to avoid revictimization such as relocation of victims (Dugan, 1999).

Noticeably absent from the literature on the economic impacts of crime is the impact of gun violence on local businesses. This is partially due to the lack of available micro-geographical level data sources on business activity until very recently. The scarcity of research on this topic is also in line with the omission of businesses from studies on the impact of crime on neighborhoods, despite the importance of local business activity as an indicator 
of the local economy and of the quality of life for residents, non-residents, and investors (Fisher, 1991; Skogan, 1986). This omission is surprising considering that the lack of legitimate local jobs for youth, and especially minority youth, has been shown to increase the likelihood that these youth engage in criminal activity (Ihlanfeldt, 2002). Furthermore, economic development efforts within Business Improvement Districts have been shown to be related to reductions in community-level incidences of interpersonal violence, which is largely experienced by youth and young adults (MacDonald et al., 2009).

Business revenues can be affected by gun violence through a variety of mechanisms. People have been shown to be afraid of places where they know violent crimes happen or where they perceive that they have a high likelihood of victimization from violent crime (see Fisher, 1991 and Skogan, 2012 for a detailed discussion) and this can affect business revenues. Although the research on the impacts of fear of crime on individuals' behavior and routine activities is somewhat inconsistent, it nonetheless suggests that some individuals may alter their routine activities and constrain their outdoor activity in response to increased perceived risk of crime (see Foster et al., 2014; Foster \& Giles-Corti, 2008; IrvinErickson, Lynch, et al., 2017b; Liska et al., 1988; Lorenc et al., 2012; Markowitz et al., 2001; Mesch, 2000; Oh \& Kim, 2009; Otis, 2007; Ross, 1993; Skogan \& Maxfield, 1981; Stafford et al., 2007). However, it is important to note that individuals' perceptions of social disorder can moderate the relationship between perceived risk and routine activities (Rengifo \& Bolton, 2012). Rengifo and Bolton (2012) found that individuals who perceive a higher level risk of victimization and a lower level of disorder engage in significantly more voluntary activities in comparison to individuals who perceive a higher level risk of victimization and a higher level of disorder. Wesley Skogan $(1986 ; 2012)$ also provides context into the relationship between social disorder on fear of crime. According to Skogan (1986; 2012), disorder can independently, but in parallel with crimes in communities, increase fear of crime and discourage investments in neighborhoods. On the topic of business patronage, Skogan (1986; 2012) and other authors (Bowes, 2007; Fisher, 1991) suggest that crime and fear of crime can reduce business revenues due to residents in high-crime neighborhoods limiting their activities and not patronizing businesses. Unsurprisingly, when business revenues are reduced, there are fewer jobs at businesses for local residents (Hamermesh, 1999; Levi, 2001).

Business owners can also change business operations and business decisions in response to crime (Bowes, 2007; Fisher, 1991; Hamermesh, 1989, 1999; Levi, 2001; Skogan, 1986; 2012). Businesses have been shown to be negatively impacted by reduced business hours, difficulty hiring employees or having employees work at undesirable evening and night business hours, and increased insurance costs due to crime. For instance, a study by Fisher (1991), based on interviews with business owners in the Hilltop Community in Columbus, Ohio, demonstrated business owners' difficulty in hiring or retaining employees who are worried about working in an environment where they perceive that they are likely to be victimized. The same study showed further harmful impacts of crime on business operations such as reduced business hours and increased business insurance costs (Fisher, 1991). Another study by Hamermesh (1989), linking Current Population Survey (CPS) data to FBI crime reports, studied time use as a nonmonetary cost of time and found that higher homicide rates in large metropolitan areas are related to a lower propensity of workers to work evenings and nights. Other studies further showcase that crime and the fear of crime can be related to decreased business investment (such as the opening of new businesses or the expansion of existing businesses) in areas with a reputation as high-crime areas (Bowes, 2007; Fisher, 1991; Skogan, 1986; 2012).

The aforementioned studies on the economic impacts of crime, along with the wider literature on the impact of crime and fear of crime on routine activities, suggest that local businesses may have difficulty attracting customers, attracting and retaining employees, or maintaining regular hours in response to heightened gun violence. To the best of our knowledge, only three studies have estimated the impact of violent crime on local businesses using business data. Rosenthal and Ross (2010) estimated the impact of violent crime on the location of businesses in Atlanta, Chicago, Houston, Indianapolis, and Seattle at the Census tract level via a cross-sectional study. The authors used two datasets for their analysis: reported crime data from local police agencies and business activity data from Dunn and Bradstreet, a for-profit firm. According to this study, an increase in violent crime during prime dinner hours ( $5 \mathrm{pm}$ to $9 \mathrm{pm}$ ) reduced the presence of high-end restaurants by roughly 40 percentage points when considering the spread of minimum and maximum number of violent crimes in Census tracts observed in the study period. In this study, restaurants are defined as high-end "if they have 1-24 employees and sales are greater than $\$ 0.5$ million, 25-49 employees and sales are greater than \$1.0 million, or 50-99 employees and sales are greater than $\$ 2.5$ million" (Rosenthal \& Ross, 2010, p. 142).

In addition to Rosenthal and Ross (2010) cross-sectional study, only two longitudinal studies have been conducted on the effects of violent crime on local business. Greenbaum and Tita (2004) used longitudinal 
business and homicide data at the ZIP code level to explore the impact of homicide surges on the creation, closing, and growth of businesses in Chicago, Houston, Miami, Pittsburgh, and St. Louis between 1987 and 1994. The authors found that local increases in lethal violence caused existing businesses to downsize and led to fewer new businesses forming. These effects were concentrated in ZIP codes where homicides were less frequent, suggesting that surges in violence in neighborhoods that already have high levels of violence may not increase the perceived risk of violence to the point of affecting business activity. The study also found that established businesses were less affected, as surges in violence had no significant impact on prompting business closures. Finally, the impact of homicide crime was greatest among personal service and retail businesses, indicating that jobs relying on face-to-face interaction between employees and customers may be most susceptible to the effects of increased violent crime (Greenbaum \& Tita, 2004).

Irvin-Erickson, Lynch, et al. (2017) estimated the impact of a sudden increase in gun homicides and gunshots on local business growth, home values, homeownership rates, and credit scores in five US cities at the Census tract level. The authors found that gun homicide surges in Census tracts reduced the growth rate of new retail and service establishments by $4 \%$ in Minneapolis, Oakland, San Francisco, and Washington, DC. The same study also found that gun homicide surges in Census tracts slowed home value appreciation by $3.9 \%$ in Baton Rouge, Minneapolis, Oakland, San Francisco, and Washington, DC. Similarly, the authors found that gunshot surges in Census tracts slowed home value appreciation by $3.6 \%$ in Oakland, Rochester, San Francisco, and Washington, DC.

We expand upon these previous studies by estimating the relationship between detected gunshots and business births, deaths, sales, and number of employees at the Census block level using data from the National Establishment Time Series Database and ShotSpotter, a gunshot detection system. While we acknowledge that gunshot detection technology has its own limitations in detecting gunshots at certain times of the day and the year and at a farther distance from acoustic sensors, data from gunshot detection technology has been shown as a valuable new data source on gun violence in the recent literature (Irvin-Erickson, La Vigne, et al., 2017a). In our study, the availability of data directly from gunshot detection technology allows us to measure the impact of actual gunshots on businesses, rather than the impact of reported gunshots on businesses, in which overreporting or underreporting are likely endogenous to neighborhood characteristics and business activity.

\section{Methodology}

\section{Data sources and measures}

The data for this study were collected from two main sources. The first is a gunshot detection system that uses a network of acoustic sensors to identify the unique audio signature of a gunshot pinpoint the location of a gunshot (Bieler \& La Vigne, 2014). The second set of data comes from the National Establishment Time Series Database, which provides point-level data on establishments including industry, location, sales, and number of employees. These data allow us to accurately measure gunshots without concern about over or underreporting in certain neighborhoods, and to link it at the point level to business location and behavior. Block-level descriptive statistics can be found in Table 1 .

\section{Gunshot data}

The gunshot data used in our analysis are based on information collected by gunshot detection technology (GDT) in Washington, DC. GDT uses a network of acoustic sensors to identify the sound of a gunshot and triangulate its position. The time and location of the gunshot are then recorded and sent to law enforcement personnel (Eng, 2004; Showen, 1997; Siuru, 2007). The newest versions of this technology have been found to accurately record gunshots under most conditions (Goode, 2012). Data used in this study come from ShotSpotter, a GDT vendor for Washington, DC. The GDT sensors covered 17.3 square miles of the city (about $25 \%$ of the total area of Washington, DC) at the time of the study (see Fig. 1). The data were made publicly available online by the Metropolitan Police Department in response to a Freedom of Information Act request. We remove incidents detected on January 1 and July 4 to minimize false positive detections from firework detonations, and we aggregate the number of gunshots detected within 500 and 1000 feet from the block edges (see Fig. 2).

\section{Establishment data}

The business location, revenue, and employment data in our analysis come from the National Establishment Time Series Database, which is an annual snapshot of Dun and Bradstreet's data on establishments, including industry, location, sales, and number of employees, among other indicators (Walls \& Associates, 2012). To limit our study to retail and service establishments with which customers are likely to interact at the establishment's physical location, we use establishments within the retail trade; accommodation and food services; personal and household goods repair and maintenance services; and personal services industries, based on the establishment's North American Industry Classification System (NAICS) code (we used establishments whose 
Table 1 Block level descriptive statistics

\begin{tabular}{|c|c|c|c|c|c|}
\hline Variable & Obs & Mean & Std. Dev & Min & Max \\
\hline \multicolumn{6}{|l|}{2010} \\
\hline Total establishments & 837 & 0.87 & 1.57 & 0 & 12 \\
\hline Total births & 837 & 0.19 & 0.48 & 0 & 4 \\
\hline Total deaths & 837 & 0.01 & 0.12 & 0 & 1 \\
\hline Total employees & 837 & 4.20 & 15.09 & 0 & 228 \\
\hline Total sales & 837 & $\$ 320,708$ & $\$ 1,413,300$ & $\$ 0$ & $\$ 20,300,000$ \\
\hline ShotSpotter Incidents $500 \mathrm{ft}$ & 837 & 19.66 & 17.45 & 0 & 122 \\
\hline ShotSpotter Incidents 500-1000 ft & 837 & 30.44 & 20.15 & 1 & 168 \\
\hline \multicolumn{6}{|l|}{2011} \\
\hline Total establishments & 837 & 0.87 & 1.57 & 0 & 13 \\
\hline Total births & 837 & 0.01 & 0.11 & 0 & 1 \\
\hline Total deaths & 837 & 0.09 & 0.32 & 0 & 2 \\
\hline Total employees & 837 & 4.17 & 14.87 & 0 & 228 \\
\hline Total sales & 837 & $\$ 302,056$ & $\$ 1,334,378$ & $\$ 0$ & $\$ 19,600,000$ \\
\hline ShotSpotter Incidents $500 \mathrm{ft}$ & 837 & 22.67 & 21.95 & 0 & 142 \\
\hline ShotSpotter Incidents 500-1000 ft & 837 & 36.49 & 29.46 & 2 & 209 \\
\hline \multicolumn{6}{|l|}{2012} \\
\hline Total establishments & 837 & 0.93 & 1.70 & 0 & 14 \\
\hline Total births & 837 & 0.16 & 0.47 & 0 & 4 \\
\hline Total deaths* & $\mathrm{n} / \mathrm{a}$ & & & & \\
\hline Total employees & 837 & 4.88 & 17.75 & 0 & 233 \\
\hline Total sales & 837 & $\$ 340,812$ & $\$ 1,501,971$ & $\$ 0$ & $\$ 22,200,000$ \\
\hline ShotSpotter incidents $500 \mathrm{ft}$ & 837 & 14.63 & 13.64 & 0 & 90 \\
\hline ShotSpotter incidents $500-1000 \mathrm{ft}$ & 837 & 24.10 & 18.45 & 0 & 127 \\
\hline
\end{tabular}

*Total deaths not calculable for 2012 since we lack data from 2013

NAICS codes began with $44,45,72,811$, or 812 ). In 2012 , approximately $25 \%$ of these types of establishments in Washington, DC fell within the GDT coverage area. Additionally, we limit the establishments to those that existed at least 1,000 feet within the GDT coverage area to ensure consistency in measuring gunshots across establishments. We geocode each establishment in these data and calculate the total sales, employees, establishment births, and establishment deaths for 2010 through 2012 at both the establishment and block level. Births and deaths were defined based on establishments entering or leaving Census blocks in a given year, rather than their existence in the dataset. A birth establishment is an establishment that did not exist at its same location in the year prior to the year of consideration. A death establishment, on the other hand, is an establishment that did not exist at the same location where it had existed a year prior. Establishments that remained in existence but moved to a different Census block are therefore counted as birth and death establishments. We convert sales for each year into 2010 dollars using Consumer Price Index conversion factors.

\section{Modeling}

To estimate the relationship between gunshots and business activity, we estimate both a cross sectional Poisson and fixed effects Poisson panel model as follows:

Cross sectional OLS:

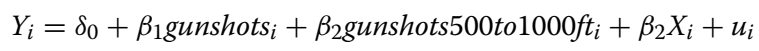

Fixed effects panel:

$$
\begin{aligned}
Y_{i t}= & \delta_{0}+\beta_{1} \text { gunshots500ft } t_{i t} \\
& +\beta_{2} \text { gunshots500to1000ft } \\
& +\beta_{3} X_{i t}+\gamma_{i}+\lambda_{t}+u_{i t}
\end{aligned}
$$

where each equation is estimated at the block level, and $Y_{i t}$ is a vector of outcome measures, including total sales and total number of employees for the establishments on block $i$ in year $t$, gunshots500ftit is the total number of gunshots within 500 feet of block $i$ or on block $i$ in year $t$, gunshots500to100 ft $t_{i t}$ is the total number of gunshots between 500 and 1,000 feet of block $i$ (or business $i$ ) in year $t, X_{i t}$ is a vector of control variables, and $\gamma_{i}$ and $\lambda_{t}$ are block and year fixed effects, respectively. We first 


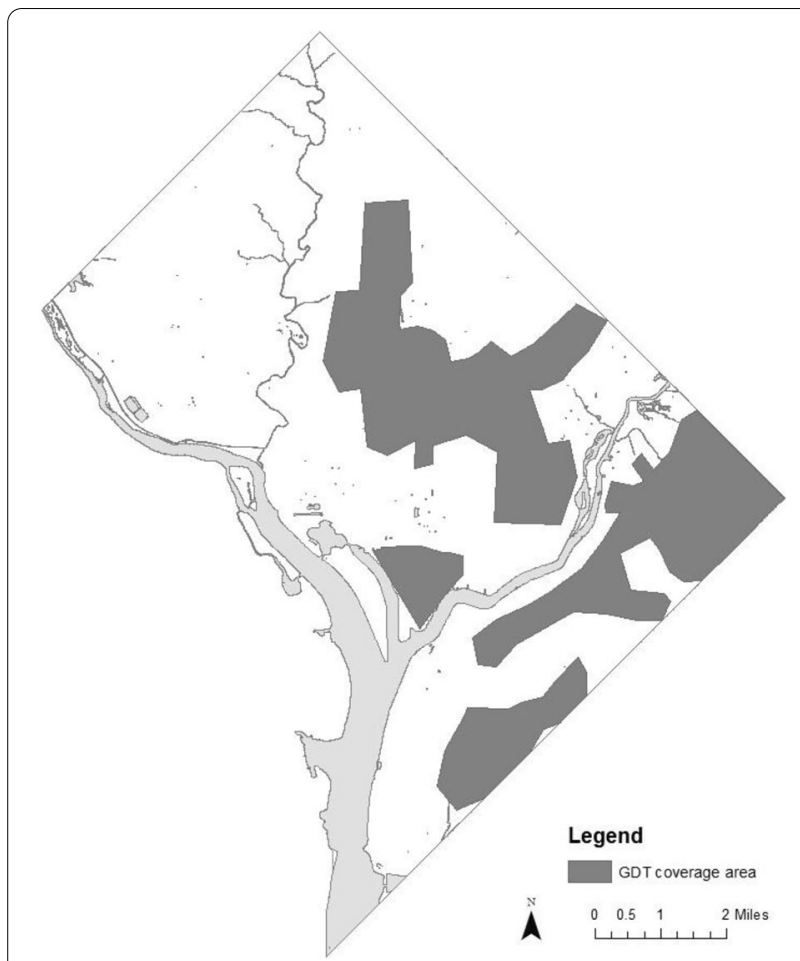

Fig. 1 Shotspotter coverage area in Washington, DC

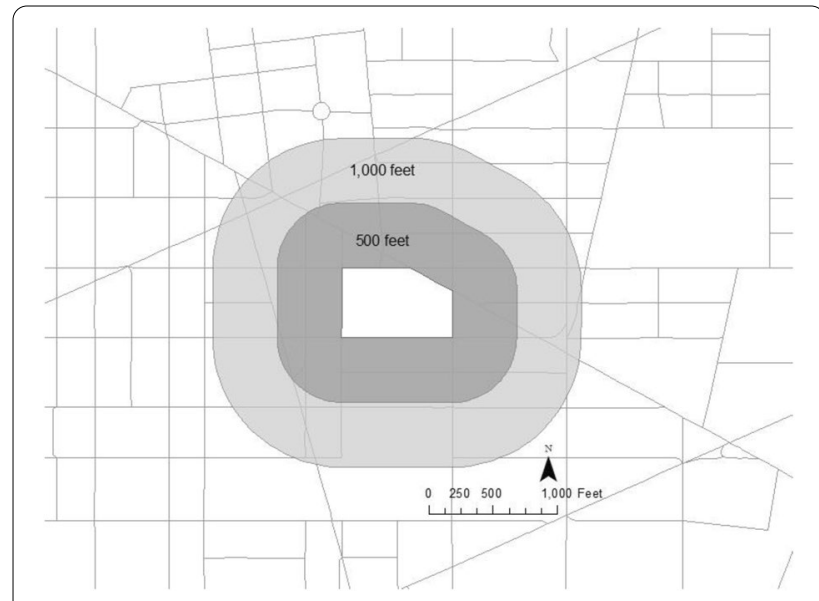

Fig. 2 Example block and buffer, 500 and 1000 feet

measure the model without the spatial lag, and then add it in to examine spillover and displacement effects. We also examine the effect of gunshots on the total number of employees using the above model, without the natural $\log$.

We also examine whether gunshots have any impact on the number of establishments, births, and deaths on each block using a cross sectional and fixed effects Poisson model, where $y_{i}$ given $x_{i}$ takes on a Poisson distribution and where $x_{i} \beta x_{i} \beta$ is specified the same as the above models.

By including fixed effects in the panel models, we remove any unobserved characteristics that are time invariant, like the geography of the area, the type of business that we are examining (for those that do not change), and any other unobserved characteristics of the business or neighborhood that do not change over time.

\section{Results}

Results indicate that across blocks, those with a higher number of gunshots also have a greater number of businesses. ${ }^{1}$ However, over time as gunshots increase, the number of service and retail businesses decline (although this effect is not statistically significant for the sample as a whole).

Table 2 displays these results. Cross sectionally, a block with 1 unit higher level of gunshots within 500 feet is associated with a $0.6 \%$ greater number of establishments (Column 1). However, when examined over time (and within block), these results switch sign, indicating that the effects seen in the cross-sectional model are due to endogeneity between gunshots and establishments rather than a causal effect: it is not the gunshots that are causing the a greater number of establishments, but rather the general correlation between commercial areas and gunshots that is causing this relationship. In fact, gunshots within 500 feet of a block decrease the total number of service and retail businesses, the number of employees employed by businesses within that buffer, and total sales for those businesses, although not at a statistically significant rate. The $95 \%$ confidence interval in the fixed effects models is $-0.3 \%$ to $0.1 \%$ for establishments, $-2.1 \%$ to $1.1 \%$ for births, $-2.8 \%$ to $2.2 \%$ for deaths, $-\$ 2,297$ to $\$ 555$ for sales, and -0.022 to 0.006 for employees.

\section{Spatial displacement and spillover}

We might be concerned that our results are attenuated because gunshots are reducing business sales in the immediate area surrounding the store and displacing it into nearby areas. To test for this, we run a spatial lag model where we include gunshots within 500 feet of the block as well as gunshots between 500 and 1000 feet of the block.

Results show that gunshots within both ranges are associated with reductions in the number of establishments, although not statistically significantly (Table 3, Column 1). Gunshots between 500 and 1000 feet of the block are, however, significantly associated with an increase in business deaths: for every additional gunshot

\footnotetext{
${ }^{1}$ Results are robust to a number of alternative specifications, including removing blocks with no establishments.
} 
Table 2 Effect of gunshots on the number of service and retail establishments, births, deaths, and employees

\begin{tabular}{|c|c|c|c|c|c|c|}
\hline & (1) & $(2)$ & (3) & (4) & $(5)$ & (6) \\
\hline & Establishments & Establish-ments & Births & Deaths & Total Sales & Employees \\
\hline & Poisson & Poisson FE & Poisson FE & Poisson FE & $\mathrm{FE}$ & $\mathrm{FE}$ \\
\hline \multirow{2}{*}{$\begin{array}{l}\text { Number of ShotSpotter } \\
\text { incidents within } 500 \mathrm{ft}\end{array}$} & $0.006^{* * *}$ & -0.001 & -0.005 & -0.003 & $-\$ 870.90$ & -0.008 \\
\hline & $(0.002)$ & $(0.001)$ & $(0.008)$ & $(0.013)$ & $(727.40)$ & $(0.007)$ \\
\hline Block fixed effects & No & Yes & Yes & Yes & Yes & Yes \\
\hline Year fixed effects & No & Yes & Yes & Yes & Yes & Yes \\
\hline Observations & 2511 & 1119 & 624 & 158 & 2511 & 1119 \\
\hline Number of blocks & 837 & 373 & 208 & 79 & 837 & 373 \\
\hline
\end{tabular}

Robust standard errors in parentheses. Fixed effects estimates are clustered at the block level

${ }^{* * *} \mathrm{p}<0.01,{ }^{* *} \mathrm{p}<0.05,{ }^{*} \mathrm{p}<0.1$

Table 3 Displacement and spillover effects of gunshots on business sales

\begin{tabular}{|c|c|c|c|c|c|}
\hline & (1) & $(2)$ & (3) & (4) & (5) \\
\hline & Establishments & Births & Deaths & Total Sales & Employees \\
\hline & Poisson FE & Poisson FE & Poisson FE & FE & $\mathrm{FE}$ \\
\hline \multirow{2}{*}{$\begin{array}{l}\text { Number of ShotSpotter incidents } \\
\text { within } 500 \mathrm{ft}\end{array}$} & -0.001 & -0.006 & -0.013 & -912.50 & -0.007 \\
\hline & $(0.001)$ & $(0.008)$ & $(0.014)$ & $(817.00)$ & $(0.007)$ \\
\hline \multirow{2}{*}{$\begin{array}{l}\text { Number of ShotSpotter incidents } \\
\text { between } 500 \text { and 1,000 ft }\end{array}$} & -0.0001 & -0.002 & $0.043^{* *}$ & 105.1 & -0.002 \\
\hline & $(0.0005)$ & $(0.007)$ & $(0.018)$ & $(466.8)$ & $(0.006)$ \\
\hline Block fixed effects & Yes & Yes & Yes & Yes & Yes \\
\hline Year fixed effects & Yes & Yes & Yes & Yes & Yes \\
\hline Observations & 1119 & 624 & 158 & 2511 & 2511 \\
\hline Number of establishments & 373 & 208 & 79 & 837 & 837 \\
\hline
\end{tabular}

Robust standard errors in parentheses. Fixed effects estimates are clustered at the block level

${ }^{* * *} p<0.01,{ }^{* *} p<0.05,{ }^{*} p<0.1$

between 500 and 1000 feet of a block, that block sees an increase of $4.3 \%$ of business deaths. This may be related to the fact that 1000 feet is the greatest distance within which a gunshot can be heard indoors (Bieler \& La Vigne, 2014), and that the power of the regression is stronger when larger areas are included in the gunshot count. However, these results hold whether we create the buffers as 500 and 1000 feet, or 1000 and 2000 feet, suggesting that the impacts on neighborhoods may be larger than the audible distance of a gunshot.

\section{Heterogeneous effects by initial level of gunshots}

Even small increases in violence in areas with lower initial levels of gunshots may have a large impact on business outcomes. Therefore, gunshots may have heterogeneous effects on business revenues based on the initial level of gunshots in the area of the business; an additional gunshot on a block with a high starting level of gunshots might not have as much of an effect as an additional gunshot on a block that usually has no gunshots at all.

To examine this hypothesis, we estimate the relationship between gunshots and commercial revenues using subsets of the data based on initial gunshot levels in 2010. Table 4 below show the descriptive statistics for these quartiles for both the block and establishment level.

These results show that impacts are, in fact, concentrated in areas with lower initial levels of gunshots. In the first quartile of blocks (i.e., blocks with the lowest number of initial gunshots), one additional gunshot is associated with a reduction of $0.5 \%$ of establishments. Gunshots on these blocks also reduce the number of business births: each additional gunshot is associated with a reduction in business births of $9.4 \%$. Surprisingly, deaths also go down on these blocks by $13.5 \%$ for each gunshot, but the overall effect on total number of establishments is still negative. 
Table 4 Descriptive statistics for quartiles of initial levels of shotspotter incidents within $500 \mathrm{ft}$

\begin{tabular}{lllcccc}
\hline Variable & Quartile & Obs & Mean & Std. Dev & Min & Max \\
\hline ShotSpotter incidents 500 ft & 1 & 155 & 3.71 & 1.75 & 0 & 0 \\
ShotSpotter incidents 500 ft & 2 & 217 & 10.00 & 2.01 & 7 & 13 \\
ShotSpotter incidents 500 ft & 3 & 230 & 17.46 & 2.79 & 14 & 23 \\
ShotSpotter incidents 500 ft & 4 & 235 & 41.25 & 18.63 & 24 & 122 \\
\hline
\end{tabular}

Table 5 Effect of gunshots on service and retail establishments by beginning level of gunshots

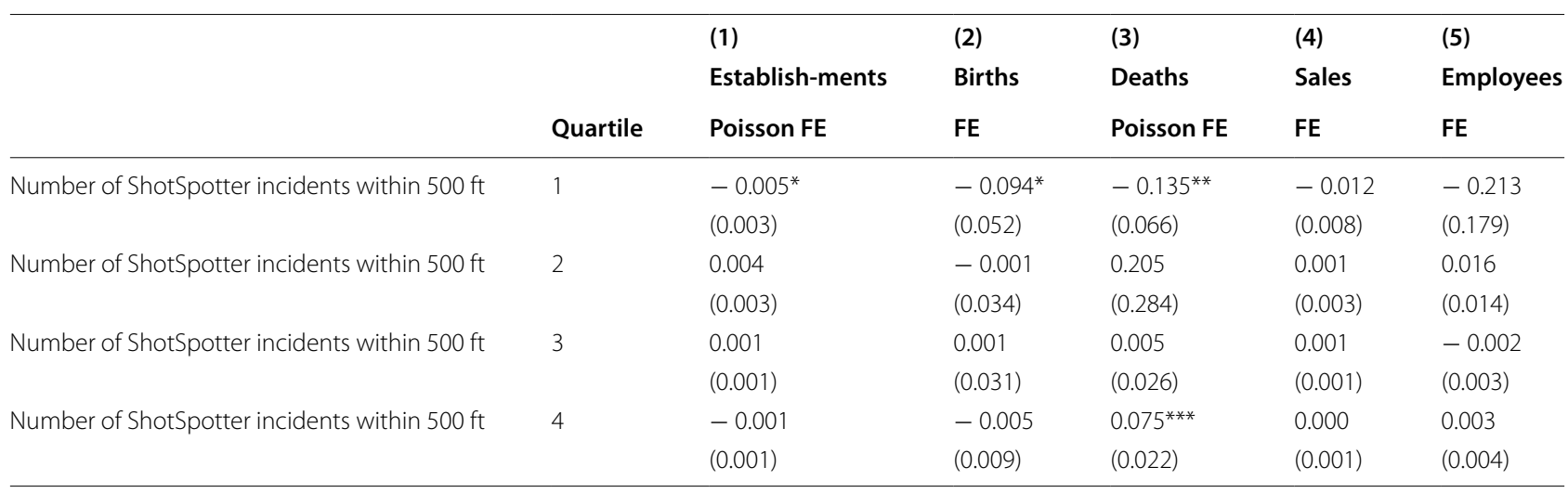

Robust standard errors in parentheses. Fixed effects estimates are clustered at the block level

Number of observations and $R^{2}$ vary by subgroup, so suppressed for brevity

*** $\mathrm{p}<0.01,{ }^{* *} \mathrm{p}<0.05,{ }^{*} \mathrm{p}<0.1$

We also see, however, a statistically significant increase in business deaths on blocks that begin with the highest initial levels of gunshots (Table 5). For each gunshot on these blocks, business deaths increase by $7.5 \%$. This implies that even areas with higher initial levels of gunshots are still affected by subsequent gunshots at the business level.

\section{Discussion and conclusions}

The dearth of studies exploring the relationship between gun violence and business activity represents a critical gap, since the level of economic activity in a neighborhood is an important indicator of the ability of its residents to build wealth. Furthermore, as discussed at the beginning of our paper, lack of local employment opportunities have important consequences, especially for minority youth (Ihlanfeldt, 2002; MacDonald et al., 2009). Absent an understanding of the specific impacts of gun violence on business activity and the causal mechanisms underlying these impacts, it is difficult to make informed policy recommendations to boost business activity in areas beset by gun violence.

Our research addresses this gap by leveraging the precision of NETS and GDT data to explore how changes in gunshots affect business revenue in areas with both higher and lower pre-existing levels of gunshots.
GDT data allow us to measure actual gunshots rather than reported gunshots, avoiding a fundamental challenge in crime literature relating to the endogeneity of crime reporting with outcomes of interest. Specifically, reported crime data may be endogenous to the characteristics of neighborhoods since neighborhoods with lower income, younger, and male victims are more likely to have underreporting of crimes while neighborhoods with a large number of homeowners are less likely to have underreporting (Skogan, 1999). Additionally, crime reporting may be higher in neighborhoods with more eyes on the street-or people to report those crimes.

Results show that, cross sectionally, blocks with a higher number of gunshots also have a greater number of businesses. However, over time as gunshots increase, the total number of service and retail businesses decline (although not at a statistically significant rate). Additionally, gunshots on nearby blocks increase the number of business deaths by $4.3 \%$, and gunshots on blocks with the lowest initial levels of gunshots (i.e., blocks in the first quartile) increase business turnover and reduce the total number of businesses present by $0.5 \%$. Perhaps surprisingly, even on blocks with the highest initial levels of gunshots (i.e., blocks in the fourth quartile), increased gunshots cause an increase in the number 
of business deaths by $7.5 \%$. These results suggest that gunshots affect businesses not only in areas with lower initial levels of gunshots, but also in areas with higher initial levels of gunshots.

These results add valuable insights into the relationship between gun violence and business activity and reinforce Rosenthal and Ross' finding that efforts to make distressed portions of cities more vibrant must give consideration to the need to ensure that such areas are safe (Rosenthal \& Ross, 2010). As discussed earlier, findings from Greenbaum and Tita (2004) and Irvin-Erickson, Lynch, et al. (2017) show that a sudden increase in gun violence reduces the growth of local businesses, especially in areas with higher pre-existing levels of gun violence. Our findings support and expand upon these studies, showing that gunshots affect the health of local businesses in both areas with the lowest and areas with the highest pre-existing levels of gunshots. Accordingly, efforts to improve distressed neighborhoods should target both areas with lower and higher pre-existing levels of gunshots. In distressed neighborhoods, business owners have a strong incentive to collaborate with local officials to reduce gun violence. Gun violence reduction efforts in communities should include business owners as key stakeholders to outline and respond to pressing issues and the needs of the community.

There is a need to build the evidence base on the impact of gun violence on local economic health. Future research should attempt to further disentangle the mechanisms through which gun violence impacts neighborhood economies and explore the relationship between gun violence and the choices of business owners and residents in communities. Local analyses of economic health are needed for devising strategies to support businesses in areas affected by gun violence. Policy recommendations for increasing revenue in areas where gun violence has decreased foot traffic, for instance, might differ from those in areas where gun violence has driven out investment. Further research in this area is necessary to fully understand the effects of gun violence on neighborhoods and provide insights to guide policy solutions. In our study, we did not explore how time of the day (i.e., day time vs. night time) affected the relationship between gunshots and business health. Furthermore, our study was based on three years of gunshot and business establishment data. Future studies can explore possible temporal mechanisms and increase the power of analyses by using a longer time span dataset.

\section{Acknowledgements}

We thank the anonymous reviewers for their time and comments.

\section{Authors' contributions}

All authors read and approved the final manuscript.

\section{Funding}

This work was supported in part by the National Institute of Justice, Office of Justice Programs, U.S. Department of Justice, Award No. 2012-R2-CX-0001 and a research grant award from Everytown for Gun Safety Support Fund.

\section{Availability of data and materials}

Not applicable.

\section{Declarations}

\section{Competing interests}

The authors declare that they have no competing interests.

\section{Author details}

${ }^{1}$ Metropolitan Housing and Communities Policy Center, Urban Institute, 500 L'Enfant Plaza SW, Washington, DC 20024, USA. ²Department of Criminology, Law and Society, George Mason University, 4400 University Dr, Fairfax, VA 22030, USA. ${ }^{3}$ Justice Policy Center, Urban Institute, 500 L'Enfant Plaza SW, Washington, DC 20024, USA.

Received: 10 September 2020 Accepted: 11 May 2021

Published online: 19 May 2021

\section{References}

Bieler, S., \& La Vigne, N. (2014). Close-range gunfire around DC schools. Urban Institute.

Bowes, D. R. (2007). A two-stage model of the simultaneous relationship between retail development and crime. Economic Development Quarterly, 21(1), 79-90.

Cook, P. J., Lawrence, B. A., Ludwig, J., \& Miller, T. R. (1999). The medical costs of gunshot injuries in the United States. Journal of the American Medical Association, 281(5), 447-454.

Cook, P. J., \& Ludwig, J. (2000). Gun violence: The real costs. Oxford University Press.

Dugan, L. (1999). The effect of criminal victimization on a household's moving decision. Criminology, 37(4), 903-930.

Eng, T. R. (2004). Population health technologies: Emerging innovations for the health of the public. American Journal of Preventative Medicine, 26(3), 237-242.

Fisher, B. (1991). A neighborhood business area is hurting: Crime, fear of crime, and disorders take their toll. Crime \& Delinquency, 37(3), 363-373.

Foster, S., \& Giles-Corti, B. (2008). The built environment, neighborhood crime and constrained physical activity: An exploration of inconsistent findings. Preventive Medicine, 47(3), 241-251.

Foster, S., Giles-Corti, B., \& Knuiman, M. (2012). Does fear of crime discourage walkers? A social-ecological exploration of fear as a deterrent to walking. Environment and Behavior, 46(6), 698-717.

Foster, S., Villanueva, K., Wood, L., Christian, H., \& Giles-Corti, B. (2014). The impact of parents' fear of strangers and perceptions of informal social control on children's independent mobility. Health \& place, 26, 60-68.

Goode, E. (2012). Shots fired, pinpointed and argued over. The New York Times. http://www.nytimes.com/2012/05/29/us/shots-heard-pinpointed-andargued-over.html?pagewanted $=$ all\&_r $=0$

Greenbaum, R. T., \& Tita, G. E. (2004). The impact of violence surges on neighbourhood business activity. Urban Studies, 41(13), 2495-2514.

Hamermesh, D. S. (1989). What do we know about worker displacement in the US? Industrial Relations: A Journal of Economy and Society, 28(1), 51-59.

Hamermesh, D. S. (1999). Crime and the timing of work. Journal of Urban Economics, 45(2), 311-330.

Hipp, J. R., Tita, G. E., \& Greenbaum, R. T. (2009). Drive-bys and trade-ups: Examining the directionality of the crime and residential instability relationship. Social Forces, 87(4), 1777-1812.

Howell, E., Bieler, S., \& Anderson, N. (2014). State variation in hospital use and cost of firearm assault injury, 2010. Urban Institute. 
Ihlanfeldt, K. (2002). Spatial mismatch in the labor market and racial differences in neighborhood crime. Economics Letters, 76(1), 73-76.

Irvin-Erickson, Y., La Vigne, N., Levine, N., Tiry, E., \& Bieler, S. (2017). What does gunshot detection technology tell us about gun violence? Applied Geography, 86, 262-273.

Irvin-Erickson, Y., Lynch, M., Gurvis, A., Mohr, E., \& Bai, B. (2017). A neighborhoodlevel analysis of the economic impact of gun violence. Urban Institute.

Kirk, D. S., \& Laub, J. H. (2010). Neighborhood change and crime in the modern metropolis. Crime and Justice, 39(1), 441-502.

Knowles, J. C., \& Behrman, J. R. (2004). The road to sustained growth in Jamaica. The World Bank.

Levi, M. (2001). Business, cities and fears about crimes. Urban Studies, 38(5-6), 849-868.

Liska, A. E., Sanchirico, A., \& Reed, M. D. (1988). Fear of crime and constrained behavior specifying and estimating a reciprocal effects model. Social Forces, 66(3), 827-837.

Lorenc, T., Clayton, S., Neary, D., Whitehead, M., Petticrew, M., Thomson, H., Cummins, S., Sowden, A., \& Renton, A. (2012). Crime, fear of crime, environment, and mental health and wellbeing: Mapping review of theories and causal pathways. Health \& Place, 18(4), 757-765.

Lynch, A. K., \& Rasmussen, D. W. (2001). Measuring the impact of crime on house prices. Applied Economics, 33(15), 1981-1989.

MacDonald, J., Bluthenthan, R. N., Golinelli, D., Kofner, A., \& Stokes, R. J. (2009). Neighborhood effects on crime and youth violence: The role of business improvement districts in Los Angeles. (Vol. 622)Rand Corporation.

Markowitz, F., Bellair, P., \& Liska, A. (2001). Extending social disorganization theory: Modeling the relationships between cohesion, disorder, and fear. Criminology, 39(2), 293-320.

Mesch, G. (2000). Perceptions of risk, lifestyle activities, and fear of crime. Deviant Behavior, 21(1), 47-62.

Miller, T. R., Cohen, M. A., \& Rossman, S. B. (1993). Victim costs of violent crime and resulting injuries. Health Affairs, 12(4), 186-197.

Oh, J., \& Kim, S. (2009). Aging, neighborhood attachment and fear of crime. Journal of Community Psychology, 37(1), 21-40.

Otis, M. D. (2007). Perceptions of victimization risk and fear of crime among lesbians and gay men. Journal of Interpersonal Violence, 22(2), 197-218.

Perkins, D. D., Brown, B. B., \& Taylor, R. B. (1996). The ecology of empowerment: Predicting participation in community organizations. Journal of Social Issues, 52(1), 85-110.
Rengifo, A. F., \& Bolton, A. (2012). Routine activities and fear of crime: Specifying individual-level mechanisms. European Journal of Criminology, 9(2), $99-119$.

Rosenthal, S., \& Ross, A. (2010). Violent crime, entrepreneurship, and cities. Journal of Urban Economics, 67(1), 135-149.

Ross, C. E. (1993). Fear of victimization and health. Journal of Quantitative Criminology, 9(2), 159-175.

Shapiro, R. J., \& Hassett, K. A. (2012). The economic benefits of reducing violent crime: A case study of 8 American cities. Center for American Progress.

Showen, R. (1997). Operational gunshot location system. In A. Trent DePersia, S. Yeager, \& S. M. Ortiz (Eds.), Surveillance and assessment technologies for law enforcement. Paper presented at the International Society for Optical Engineering, Boston, MA, 130-139.

Siuru, B. (2007). Gunshot location systems. Law and Order, 55(10), 10-12.

Skogan, W. (1986). Fear of crime and neighborhood change. Crime and Justice, 8, 203-229.

Skogan,W. G. (1999). Measuring what matters: Crime, disorder, and fear. In R. Longworthy (Ed.), Measuring what matters: Proceedings from the Policing Research Institute Meetings. Washington, DC: U.S. Department of Justice.

Skogan, W. G., \& Maxfield, M. G. (1981). Coping with crime: Individual and neighborhood reactions. Sage Publications.

Skogan WG (2012) Disorder and crime. The Oxford handbook of crime prevention, pp 173-188.

Stafford, M., Chandola, T., \& Marmot, M. (2007). Association between fear of crime and mental health and physical functioning. American Journal of Public Health, 97(11), 2076-2081.

Tita, G. E., Petras, T. L., \& Greenbaum, R. T. (2006). Crime and residential choice: A neighborhood level analysis of the impact of crime on housing prices. Journal of Quantitative Criminology, 22(4), 299.

Walls \& Associates. (2012). NETS: National establishment time-series database. Author.

\section{Publisher's Note}

Springer Nature remains neutral with regard to jurisdictional claims in published maps and institutional affiliations.
Ready to submit your research? Choose BMC and benefit from:

- fast, convenient online submission

- thorough peer review by experienced researchers in your field

- rapid publication on acceptance

- support for research data, including large and complex data types

- gold Open Access which fosters wider collaboration and increased citations

- maximum visibility for your research: over 100M website views per year

At BMC, research is always in progress.

Learn more biomedcentral.com/submissions 